\title{
In-Flight Manual Electronics Repair for Deep-Space Missions
}

\author{
Richard Pettegrew and John Easton \\ National Center for Space Exploration Research \\ 21000 Brookpark Road, MS 110-3 \\ Cleveland, $\mathrm{OH} 44135$ \\ 216-433-8321 \\ Richard.Pettegrew@grc.nasa.gov \\ 216-433-2643 \\ John.Easton@grc.nasa.gov \\ Peter Struk \\ NASA Glenn Research Center \\ 21000 Brookpark Road, MS 110-3 \\ Cleveland, $\mathrm{OH} 44135$ \\ 216-433-5948 \\ Peter.Struk@nasa.gov \\ Eric Anderson \\ ZIN Technologies, Inc. \\ 2001 Aerospace Parkway \\ Brook Park, OH 44142 \\ 216-925-1063 \\ andersone@zin-tech.com
}

Abstract-Severe limitations on mass and volume available for spares on long-duration spaceflight missions will require electronics repair to be conducted at the component level, rather than at the sub-assembly level (referred to as Orbital Replacement Unit, or 'ORU'), as is currently the case aboard the International Space Station. Performing reliable component-level repairs in a reduced gravity environment by crew members will require careful planning, and some specialty tools and systems. Additionally, spacecraft systems must be designed to enable such repairs.

This paper is an overview of a NASA project which examines all of these aspects of component level electronic repair. Results of case studies that detail how NASA, the U.S. Navy, and a commercial company currently approach electronics repair are presented, along with results of a trade study examining commercial technologies and solutions which may be used in future applications. Initial design recommendations resulting from these studies are also presented. $^{1,2}$

\section{TABLE OF CONTENTS}

\section{INTRODUCTION} 1

\footnotetext{
${ }^{1}$ U.S. Government work not protected by U.S. copyright.

2 IEEEAC paper \#1208 Version 3, Dec. 20, 2006
}

2. Case Studies ................................................3

3. TRADE STUdY RECOMMENDATIONS .............. 7

4. SOLDERING TECHNOLOGIES ......................... 10

5.SUMMARY \& RECOMMENDATIONS ..............13

ACKNOWLEDGEMENTS.................................14

DISCLAIMER ..................................................15

REFERENCES.................................................15

BIOGRAPHY...................................16

\section{INTRODUCTION}

One of the major constraints on long duration space flight, particularly missions beyond low Earth orbit (LEO), are the limits on mass and volume of payload that must be carried. Deep space missions will require a degree of selfsufficiency by the astronauts, greater than any previously encountered. This will lead to conflicting constraints requiring an adequate quantity of spare parts, such that the crew can perform repairs during the mission without logistical support from Earth, but with minimal mass and volume. 
The flexibility to respond decisively to unforeseen problems is a crucial issue for deep-space missions, with implications to operational concepts, logistical strategies, and system hardware designs. The Apollo 13 crew survived and returned to Earth due to their ability to re-work life support systems when the service module tank exploded. In tragic contrast, the loss of the orbiter Columbia illustrates the other extreme, in which even if the crew had been aware of the wing damage incurred at liftoff, they were not equipped to make in-flight repairs. In the wake of this accident, significant efforts have been made to make such repairs possible on subsequent missions.

\section{Current Electronic Repair Strategy: Orbital Replacement Units}

With respect to electronics repairs, the traditional approach on platforms such as the International Space Station (ISS) has been board-level replacement of orbital replacement units (ORUs), regardless of what component failed in the unit. This approach requires regular, comparatively large volume re-supply missions to be effective. While this has been a less serious limitation for low Earth orbit (LEO) missions such as the ISS, where periodic re-supply of ORUs can be performed, this method of operation becomes more limiting in the case of deep-space missions, where an acceptable margin of safety for the crew may require multiple replacement capabilities (in case of recurring failures) for each of the potentially thousands of electronic boards on board the spacecraft, without possibility of resupply. This means that mission planners must choose between:

1. Oversizing the spacecraft to accommodate the large number of spare ORUs needed for proper safety margin, resulting in much greater vehicle costs,

2. Placing severe limits on the number of spares that are carried, resulting in greatly increased risk to crew and mission, and/or

3. Developing and implementing the capability for component-level repairs executed by the flight crew, such that a repair capability sufficient to maintain an acceptable margin of safety is maintained, while still minimizing the mass and volume required to provide that capability.

Given these options, component-level repair is clearly the pragmatic choice for deep-space missions, since the cost of bringing sufficient spare ORUs is great and the safety of the crew and mission cannot be compromised.
Potential Cost-Savings of In-Flight, Component-Level Repairs

Accompanying the reduction in upmass that is enabled by component-level repair is a corresponding cost-savings. These savings are realized most significantly through savings in launch costs, where each pound of payload to the moon is estimated to cost on the order of $\$ 100,000$ [1], and $\$ 10,000$ per pound to low Earth orbit. Further savings are realized through the reduced need to procure spare ORU's, and in general, by reducing the size of the "logistical train" needed to sustain the mission.

These issues were examined by Accola and coworkers [2], who used a numerical model called the Model for Estimating Space Station Operations Cost (MESSOC) to evaluate the effects of changing a variety of parameters, including in-orbit repair of ORU's, on the cost and available crew time onboard the space station (at the time of publication, the proposed Space Station Freedom). In this study, the authors assumed the flight crew performed $10 \%$ of all electronics repairs, and used the cost and time for this level of repair as a reference standard. The results of this modeling predict that increasing the percentage of crew repairs from $10 \%$ to $30 \%$ decreased crew time available for other tasks by $2 \%$, but eliminating all crew repair activities added only $1 \%$ to available crew time. Similarly, increasing the amount of crew repair from $10 \%$ to $30 \%$ saved $2 \%$ of the operating cost, and eliminating crew repair added $1 \%$ to the operating cost. While this study did not examine component or tool mass, volume, and power requirements on the station, it did look at the effect of crew repair on shuttle re-supply upmass. Increasing crew repairs from $10 \%$ to $30 \%$ led to a predicted decrease of $20 \%$ in shuttle resupply upmass, while eliminating crew repairs led to a $10 \%$ increase in shuttle re-supply upmass. These savings (or losses) in shuttle re-supply upmass have implications with the proposed practice of conducting component level repairs in long duration space missions. In Accola's model, planning for crew repairs saved a substantial amount of mass and volume compared to simply removing a faulty ORU and swapping it with another unit, usually a unit delivered from the ground. Similarly, crew repairs of faulty ORU's during space missions will save volume and mass by not requiring full-sized ORU replacements.

\section{Component-Level Repair for Future Missions}

The recommendation for repair at the lowest possible levels has been expressed in NASA's Exploration Systems Architecture Study (ESAS) document, which states (Section 7.2.2.4.3) "The logistics footprint required to support exploration missions must be minimized. Strategies to achieve this objective include broad implementation of commonality and standardization at all hardware levels and across all elements, repair of failed hardware at the lowest 
possible hardware level (as determined on a case-by-case basis by detailed analyses) ....”[3].

Similar recommendations are found in other documents. Draft versions of the Constellation Architecture Requirements Document (CARD) already contain guidelines requiring the "supportability" of the mission including commonality, interchangeability, and maintainability across all elements of the exploration system. Section 3.1.2 of the CARD states that "hardware should be designed from the initial design-phase for ease of repair and maintenance, due to the time and distance affects on the logistics of re-supply and the effects of hardware failure on long duration mission risk," [4]. Clearly, these requirements can only be met if they are included in the early design phase of the mission. By incorporating reparability concepts into the CEV and other programs early, NASA will establish a precedent for designing electronics for repair and laying a foundation for component level repair by crew members. Component-level repair of electronics (which is addressed in the Supportability Technology Development Project Plan, part of the Exploration Systems Technology Development Program) directly addresses the previously noted requirements set forth by NASA guidelines.

However, the issue of electronics repair is not settled by simply deciding to perform component-level repair. These repair operations and procedures must be determined and validated with respect to the microgravity environment in which they would be carried out. For example, recent research has shown an increase in solder joint porosity in reduced gravity compared to normal gravity, without any indications of the porosity increase on the surface of the solder joint $[5,6,7,8,9]$. This previous work, as well as the work of Grugel and coworkers [10], also demonstrate the ability to solder electrical components in reduced gravity. In addition to these experimental results, other difficulties can be fairly assumed during soldering operations in reduced gravity, such as placement and alignment of the component prior to soldering, dealing with issues surrounding conformal coating removal and reapplication, etc. These difficulties do not limit the potential benefits of a component-level repair modus, but they undeniably require time and effort to develop effective procedures, such that the crew can perform reliable repairs at the crucial moment in the mission where it is required.

Further, it is likely that, during the process of determining how component-level repairs can be made in the microgravity environment, limitations on what components or configurations can be repaired could be encountered. This clearly requires that the efforts to determine the practical procedures, techniques, and devices required for repairs must be done prior to, or at least in parallel with, the development of the spacecraft and its electronic subsystems, such that knowledge gained from the development of the repair efforts can positively influence the designs of the electronics, and therefore make them amenable to repairs.
Only with this "hand-in-hand" effort can the full benefits of effective repair capability with mass and volume savings be completely realized.

\section{CLEAR: Component-Level Electronics-Assembly Repair}

CLEAR, which stands for Component-Level ElectronicsAssembly Repair, is a NASA task, funded through the Supportability Project through NASA's Exploration Technology Development Office. The goal of CLEAR is to develop the capability to perform component-level repair of electronics on long-duration space missions. This paper summarizes the results of a trade study [11] performed by the CLEAR team, as part of early efforts to develop this repair capability. Emphasis is placed on the results of three case studies, which were performed to evaluate the methods and resources used to perform electronic repair by NASA, the U.S. Navy, and a commercial company. The recommendations from the trade study (based on both the case studies and on a comprehensive review of current technologies available for the elements of the repair process) are also summarized, and a brief discussion is given of certain future elements of the CLEAR task.

\section{Case Studies}

An investigation of repair practices in reduced gravity initially requires an examination of current practices in various laboratory and industrial settings. Accordingly, case studies were conducted to examine the repair process from three differing perspectives, covering a range of arenas in which electronic repair is currently performed. These case studies include NASA's current methods for ground-based electronic repair, the U.S. military (as embodied by the Crane Division, Naval Surface Warfare Center), and a commercial electronics fabrication company (Matric Limited). These examples will illustrate the manufacturing, repair, and related processing performed by this range of electronic producers and users.

\section{Case 1: NASA Electrical Power and Control Unit (EPCU)}

The development of flight hardware for NASA applications is performed both internally and externally. The following example represents the difficulty of contracting the design, but is representative of any small quantity production item. The Electrical Power and Control Unit (EPCU) was developed to be a generic power distribution system for ISS $[12,13]$.

The development of the power conversion and soft switching of loads was a joint effort between NASA Glenn and Sunstrand located in Lima, OH. Sunstrand later merged with Hamilton and eventually was purchased by Allied Signal. The Lima, OH, location closed, with work and 
personnel transferred to Rockford, IL [14]. The Rockford facility manufactured qualification and flight units, with board population work sent to a division in Phoenix, AZ. The manufacturer supported extensive qualification testing, such as electro-magnetic interference (EMI) as well as thermal and vacuum testing, performed at various locations [15]. The manufacturer's testing of the flight units was limited to functional acceptance tests due to funding constraints. Allied Signal supplied each flight unit with asbuilt mechanical and electrical drawings.

The manufacturer generated internal sub-system and board level tests. Board level testing was performed with the developmental system. The developmental system was an engineering breadboard model of the EPCU. The developmental system had been modified installing switches and breakout points to simplify the performance of the tests. [15].

\section{Case 2: Crane Division, Naval Surface Warfare Center (NSWC)}

Located in Crane, Indiana, NSWC Crane provides support for the maintenance of the Navy's electronic systems. This includes providing a repair depot service. Crane also supports initiatives to provide the ability to perform repairs in the field. This includes recommending tools and spare parts to be used at remote locations, including aboard ships.

The Navy segregates how electrical assemblies are serviced. The tooling and support services required to perform repairs are dictated by the criticality of the system being maintained by examining the impact on the ship's operations if the system is not operating properly.

- For shipboard electronics, all on-board repairs are authorized by Fleet policy. The technician(s) performing the repair and requirements for the ship will dictate how many repairs are performed verses being offloaded to a supply depot for repair and/or disposition. The diagnostic tools at this level may be limited to non-powered in-circuit measurements [16].

- For aviation electronics, support personnel and equipment are provided to perform on-site repairs. This includes a full complement of tools, spares, and functional testers [16].

- The approach for submarines is different from fleet and aviation electronics. Sufficient sub-assembly spares are provided so that on-board repairs are typically not performed. Submarine crews return suspect hardware to a supply depot for evaluation and repair. The on-board diagnostics are limited to built-in tests for the different systems [16].
NSWC Crane provides a centralized service for repairing fleet electronics, handling items that cannot be repaired in the field. Due to the nature of sub-contracting and the longevity of the hardware lifetime, schematics for the associated hardware are often not available to Crane. Lacking that documentation, the usage of dedicated and automated functional testers provides acceptance criteria for electrical assemblies.

The Teradyne system shown in Figure 1 is an example of a functional tester. The system applies power to the board and excites and/or measures the board external inputs, depending on the configuration of the Teradyne system. These systems include a combination of custom cards and off the shelf test equipment [17]. Avionics repairs have a similar functional tester, the Consolidated Automated Support System (CASS), shown in Figure 2. This is a custom designed test bed for avionics systems.

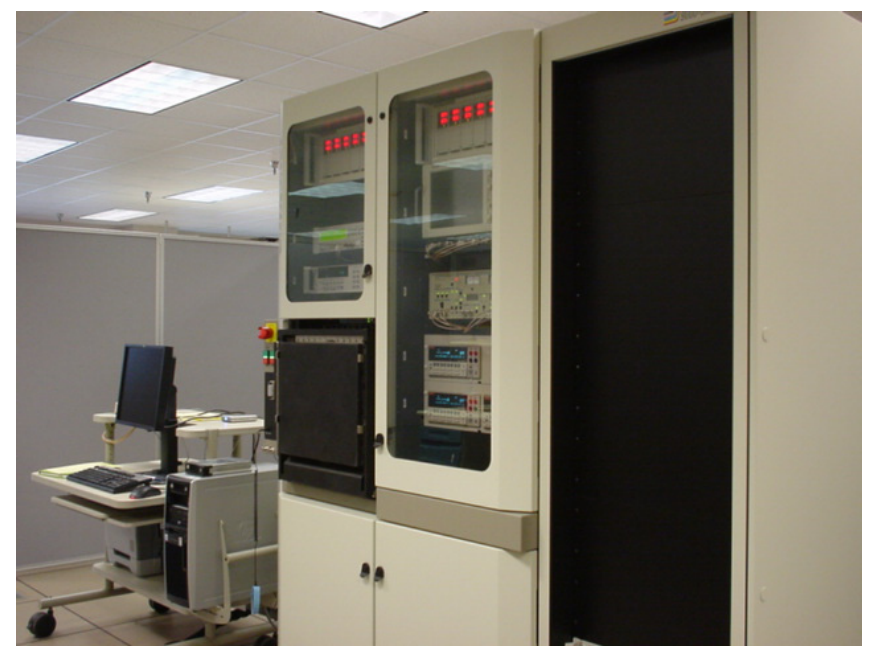

Figure 1 Teradyne Spectrum function tester [17 ]

The information provided by the functional testers allows Navy technicians to narrow the search for faults to specific sections or functions of a board. The functional testers do not find specific faulty components because they are limited to testing at the interface connectors. The Navy has adopted the usage of in-circuit testers for identifying problematic components on a suspect board [16]. Two different types of in-circuit testers are used: Huntron and the DiagnoSYS PinPoint system. The Huntron testing method focuses on comparing the suspect board against data from known good boards (typically data from three good boards generates a baseline). With the Huntron system, the non-functional test generates current-voltage (I-V) curves at each node across the board. Pre-defined test sequences can be generated to test sub-sections of the circuitry to improve throughput. The PinPoint system provides both the I-V curve capability as well as methods to perform functional tests on components in-situ. For in-situ functional testing, PinPoint systems supply power to the card, and component inputs are overdriven for short periods of time to verify functional 
operation. The in-situ testing also requires comparison against data from known good boards.

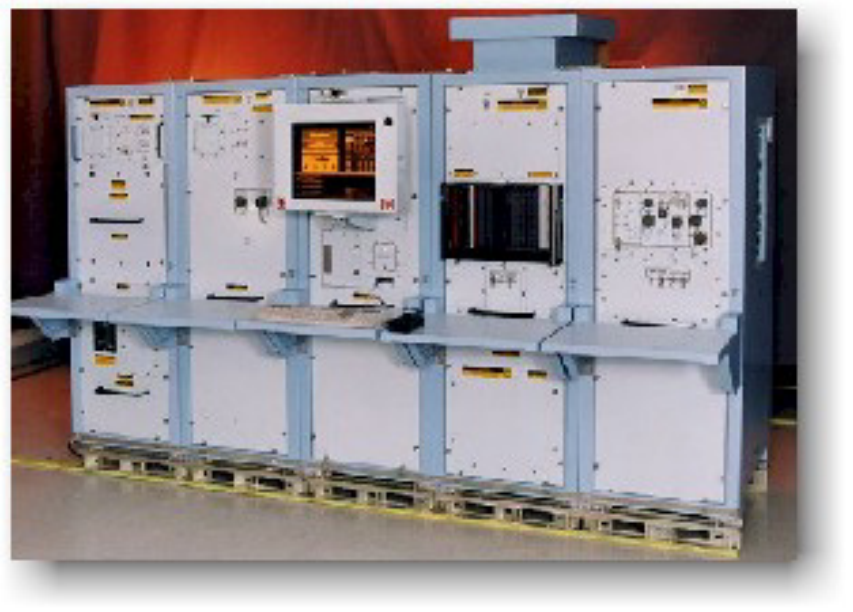

Figure 2 CASS System [16].

The U.S. Navy also provides repair information including procedures, circuit characteristics, and diagnostic information. This Gold Disk program allows for the repair of complex circuits at the point of use (onboard ship or in the field), increasing the functionality of the unit and decreasing the cost of repair. Gold Disks may also contain information regarding the I-V curve response from a nonfunctional tester, allowing comparison between the faulty circuit and a "known good" circuit and timely diagnosis of a problem [16].

\section{Case 3: Matric}

Matric is an electronics manufacturer located in Oil City, PA, building and populating new circuit boards and providing repair services. They serve a variety of customers including mining, medical, and customers with IPC-610 class 3 requirements (high-reliability and military applications). Matric has invested significant efforts in a computerized manufacturing control system. This has included improvements to aide in tracking of assemblies through-out the process, such as bar coding.

A variety of testing services is available for new production. Matric has automated vision systems capable of identifying problems with component placement. Also, they use a flying prober extensively. Using the gerber file data, all components are tested in-situ to verify that the proper components are installed. For integrated circuits (IC), this is typically limited to diode checks to verify that the IC's orientation is correct. A dedicated inspector performs a visual inspection at this point. The card will either be functionally tested or installed into a higher level of assembly and tested. This is typically performed by installing the item into a system that emulates the final application [18].

\section{Process Overview}

The chart shown in Figure 3 represents the high-level steps performed during the assembly and repair processes. As previously mentioned the overall process is identical for the different case studies. The difference is with the implementation.

For the assembly of new electrical systems, NASA produces small quantities. A large amount of engineering support is provided during the build process. A large portion of the assembly is performed by hand. Testing is performed with bench top test equipment and dedicated test fixtures. For commercial board builds, the design is assumed to be matured and automation is required to reduce cost. This requires the transfer of information (bill of material, gerber files, schematics, and test procedures). Non-functional testing may be performed to reduce assembly error (visual inspection and on-situ component measurement). Final product testing is performed in a manner similar to NASA testing.

During the repair process for both NASA and commercial applications, the diagnostic process uses benchtop test equipment and dedicated test fixtures. This approach requires a high level of skill from the operator. Automated test systems are available; however, these systems are expensive both in initial cost and set-up time for each board. NASA and commercial manufacturers also perform repairs immediately after manufacture and testing, before shipment to the purchaser or user. While these aspects are important and offer insight into electronics repair in general, they are not typical of the repair case studied in this paper, where the electronics are installed and in use prior to a fault. When NSWC Crane is performing repairs for the U.S. Navy, automated testers are used to perform testing at the board level. To minimize cost, non-functional testers are used to debug problems internal to the board. The non-functional testers perform characteristic measurements (I-V curves) for the different nets internal to the card. These are compared against known good curves to determine the location of the fault. The experience of the U.S. Navy is more applicable to the current study, because in both cases the electronics have been in use prior to a fault, and repairs are to be conducted locally rather than by the manufacturer. The technicians in the cases of the U.S. Navy or the current study, the mission crew members, do not have the specific education, training, or experience of technicians performing repairs in the first and third case studies. 


\section{Case Study Summary}

The review of manufacturing and repair processes is intended to highlight key features from NASA, industry and the military. The processes used for repair are identical, differing in the implementation. The processes includes: functional testing at the unit or sub-system level, diagnosing at the board level, and replacement of components. The ability to perform functional testing at a sub-assembly/ ORU level will be required on-orbit. To diagnose problems at the board level, alternative methods can be used for testing: review of design documentation, performance of built-intest, and non-functional testing. These approaches will require maintenance of full system documentation, even of proprietary design information and software, as the system may have to be re-programmed after replacement of some components. Further, a detailed database of the electronic signatures of known good boards and components must be developed and maintained to enable effective non-functional testing. Volume and mass constraints will require modified versions of the strategies and equipment employed by industry and the military, including the pursuit of component standardization and uniformity, to minimize specialty tools needed for repair and to minimize the total number of spare components required.

The ability to replace components during the mission will depend upon the tooling provided and the skill and training of the personnel, who may not have the experience in electronics repair of ground-based technicians. Further, the practicality of making electronic repairs at the component level can be affected greatly by upstream design considerations, ranging from board accessibility to electronics design aspects, to choice of conformal coatings. NASA should consider reparability by trained, but not expert, astronauts early in the design process. These aspects include the selection of component lead pitch and length, layout of components on the board, accessibility to the circuit boards within a module for removal and replacement, and any other factors easing the repair task for crew members. Each of these aspects was examined during the CLEAR trade study, with the findings and overall recommendations summarized in the following section.

\section{Repair}

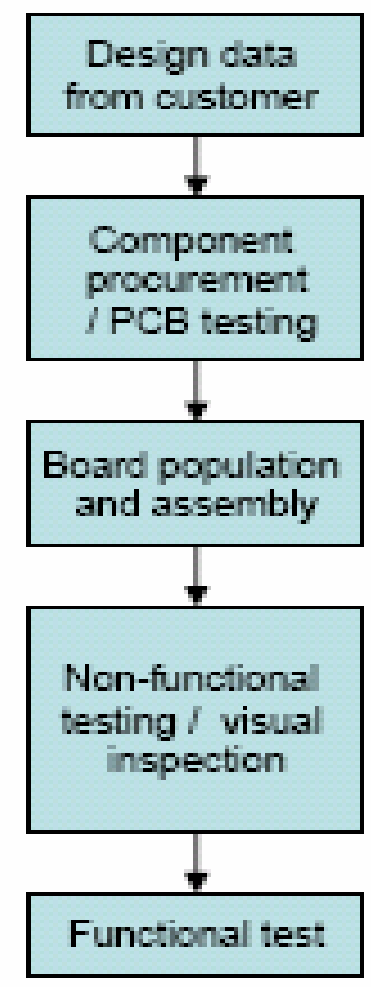

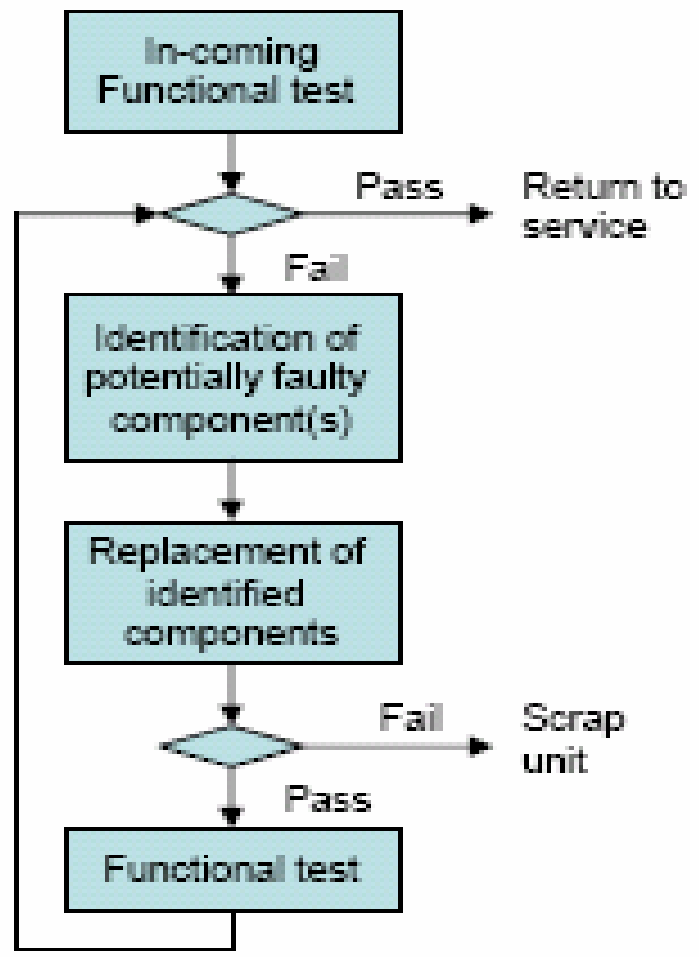

Figure 3 Common assembly and repair processes flow chart. 


\section{TRAde StUdy Recommendations}

\section{Diagnostics}

The selection of test equipment for long term missions will be based on the available volume, mass, and crew skill level. The ability to diagnose problems will be limited by the ability to perform in-situ tests, and by the limitations of the equipment selected. For installed equipment, such as an ORU that has not been removed to the on-board work area, the available test equipment will probably be limited to a scope-meter and/or voltmeter with current probes. This will be augmented with the ability of sub-systems to perform functional tests. Repair and testing of damaged sub-systems would be performed off-line.

To minimize the on-orbit resources required, a diagnostic system needs to allow performance of both functional and non-functional tests. Existing modular test hardware can perform the majority of common electrical measurements required for functional testing. Additionally, hardware required for the performance of non-functional testing (such as generating I-V curves) could reside in the same system. The system should include:

- X-Y stage for non-functional test. This would allow automated probing of board nets and the performance of visual inspections. This will require provisions for the automated probe to penetrate conformal coating on the faulty board, and for the crew to "touch up" the coating on test locations.

- Telemetry interface. It is expected that the diagnostic effort will be developed for specific problems. The general approach and equipment required will be common, but specific test routines will need to be developed for each item or problem encountered. It is expected that this will become a post-flight activity to minimize the associated cost.

- Diagnostic engine. This will probably consist of a PXI system. The system will include cards for a processor, cards to support the non-functional testing, cards to support common spacecraft interfaces, and to provide generic electrical measurement capability (voltmeter, oscilloscope, etc.).

- Power supply. The performance of functional testing will require that power is supplied to the unit under test. The power supply will be the heaviest item required. The number of outputs and power rating will drive the final weight. To reduce weight, only common sub-system voltage will be supplied.

\section{Conformal Coatings}

The conformal coating, used to protect the circuit board and components from environmental damage (and also as protection against fire hazards [23]), can also be a hindrance to component-level repairs. The difficulty of repairing a coated board lies primarily in the removal of the coating; different techniques are required for removing different types of coatings, and some of these techniques are not practical for use in a spacecraft environment. Therefore, careful selection of the conformal coating to be used for flight systems is necessary to preserve the capability of component-level electronic repairs. Failure to consider and address this issue properly can virtually eliminate (or at least greatly complicate) the practicality of component-level electronics repair during a mission.

A variety of conformal coatings exist [19], each of which is useful in certain environments and applications. However, the unique constraints imposed by the need to perform repairs in a spacecraft environment (with extremely limited support infrastructure available) limit the choice of coatings. Specifically, the coating must be easily removable using hand tools only, with no chemicals. The constraint of using only hand tools arises from the need to minimize the mass and volume of support infrastructure, which excludes coatings that are typically removed using abrasive means such as micro-blasting [20]. The closed environment of a spacecraft or surface habitat also precludes the use of chemicals or solvents, narrowing the range of coatings further.

The properties of all common conformal coatings were examined during the CLEAR trade study [11]. The result of this study showed that the coating best suited to enable inmission repair is silicone RTV (room temperature vulcanizing, meaning that the compound 'cures' at room temperature). NASA standards require a thickness between 0.002 and 0.008 inches for cured silicone coatings [21]. Primed coatings, however, are difficult to remove, and the CLEAR trade study recommends a thicker coating of unprimed silicone coating. This coating may be easily removed with simple hand tools, but testing must ensure the coating conforms with electronics and flammability requirements, such as the tests described in [22].

\section{Desoldering, Cleanup, and Resoldering}

Component Removal-After removing the conformal coating, removal of the damaged component is the next step in the repair process. There are two general methods for removing a damaged component from a circuit board, destructive and nondestructive. Each method requires certain skill levels and tools, and each has its own strengths and weaknesses.

One problem with component removal in either destructive or nondestructive techniques is the use of an adhesive 
holding the component to the circuit board. Manufacturers use adhesives to ensure alignment of a component or if the manufacturing process requires rotating the circuit board prior to soldering. If the adhesive is strong or applied in a large quantity, removing the component can be difficult and may damage the board under the component. For this reason, the use of adhesives under circuit components is not encouraged in applications where crew repair is desired. If adhesives are used in the manufacturing process, destructive removal of the component may be the only option available to repair the board, though this can vary on a case by case basis.

Destructive Removal-Destructive removal entails cutting away the leads of a damaged component with a hand tool, most likely a pair of wire cutters. The user cuts the component lead between the component body and the solder joint, one lead at a time, until all the leads are cut and the component removed. While mechanical damage to a circuit board can result from cutting the leads of a component, this is a rare occurrence (though somewhat more common in cases with reinforced leads or ceramic circuit boards). These potential hazards can be minimized, if not eliminated, with training. Next, the user desolders the remaining legs from the circuit board, heating the solder joint with a soldering iron and removing the leg with tweezers or similar tool. The crew member must then clean the solder pads on the circuit board as discussed later, and solder the replacement component into place. This technique is simple and does not require any skills beyond general soldering techniques.

Destructive removal of the component does suffer some drawbacks. These include further damage to the faulty component, making post-flight analysis difficult or impossible. Destructive component removal also requires more time to clean and prepare the circuit board before soldering in the new component, compared to the time required when using the non-destructive method. This incremental time increase is balanced, though, by the reduced level of skill required, and the lower risk of board damage.

Nondestructive Removal-Generally, nondestructive removal involves heating all of a surface mount component's solder joints simultaneously and lifting the whole component off the circuit board after reflowing the solder. For through-hole components, users desolder each leg individually. This technique requires more tools (sometimes, specialty tools) than the destructive removal technique. Nondestructive removal utilizes a soldering iron or other heat source to heat and reflow the solder joints of a component prior to removal. When performed with a soldering iron, this requires different size and shape tips to accommodate different component configurations; Figure 4 shows a small sample of these tips. The use of these various tools requires more training and skill than the destructive method, and the use of additional tools presents a larger, though not especially difficult, logistics challenge in terms

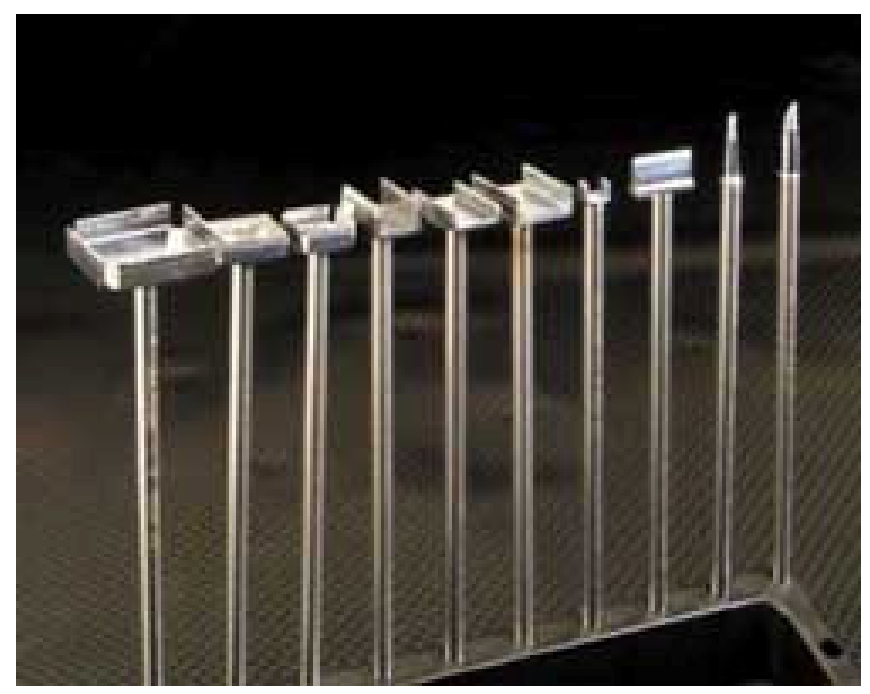

Figure 4 A selection of soldering iron tips. Different sized chips require unique soldering iron tips [1].

of packing, stowing, and usage of the various tools. This technique also presents a greater risk of damaging the circuit board or other circuit components than the destructive method. Users may overheat the board, damaging lands, or may damage a board by lifting a component with one or more solder joints not fully melted. Nondestructive removal does preserve the faulty component for future analysis, and requires less cleaning of the board prior to component replacement. Crew members may also use nondestructive removal of components to scavenge a component from a less critical board for use in a more critical, faulty board. This could be important in cases where a spare component is unavailable.

Board Cleanup -After removing conformal coating and the faulty component, the crew member must desolder the leads remaining after removing the component and clean the solder pads or plated through holes prior to placing and soldering the new component. These steps are important because debris and residue left from the coating and component removal steps will interfere with the new solder joint flowing and bonding the component leg to the circuit board. Debris and residue may also contribute to the formation of voids within the new solder joint, which could reduce the reliability of the joint mechanically, thermally, and electrically, leading to additional damage in the future [9]. Board cleanup is an important step in the repair of a damaged or faulty circuit board.

The first step to cleaning a circuit board is to remove any large debris left behind while removing conformal coating and the component legs. Dental tools or a pointed wooden stick may remove conformal coating debris, with the crewmember scraping the area with the tool. The facility used should have access to a vacuum line to remove debris particles should they become airborne.

Excess solder and component legs remaining on the plated through hole or land of the circuit board must also be 
removed prior to replacing the component. The crew may remove the solder using solder wick and the soldering iron, a suctioning syringe designed for removing solder with the soldering iron, or a combination soldering iron and suction pump specifically designed to remove solder. Two examples of such systems are the MFR-DSI from OK International [23], and the WRS1002X from Weller [24]. Figure 5 shows one such tool in use for removing solder from a circuit board. Many soldering iron manufacturers, including those listed in the following section, manufacture these soldering tools as part of their standard product line. The user must take care in removing the solder; the application of too much heat can cause damage to the circuit board, which is much more difficult to repair than the removal and replacement of components.

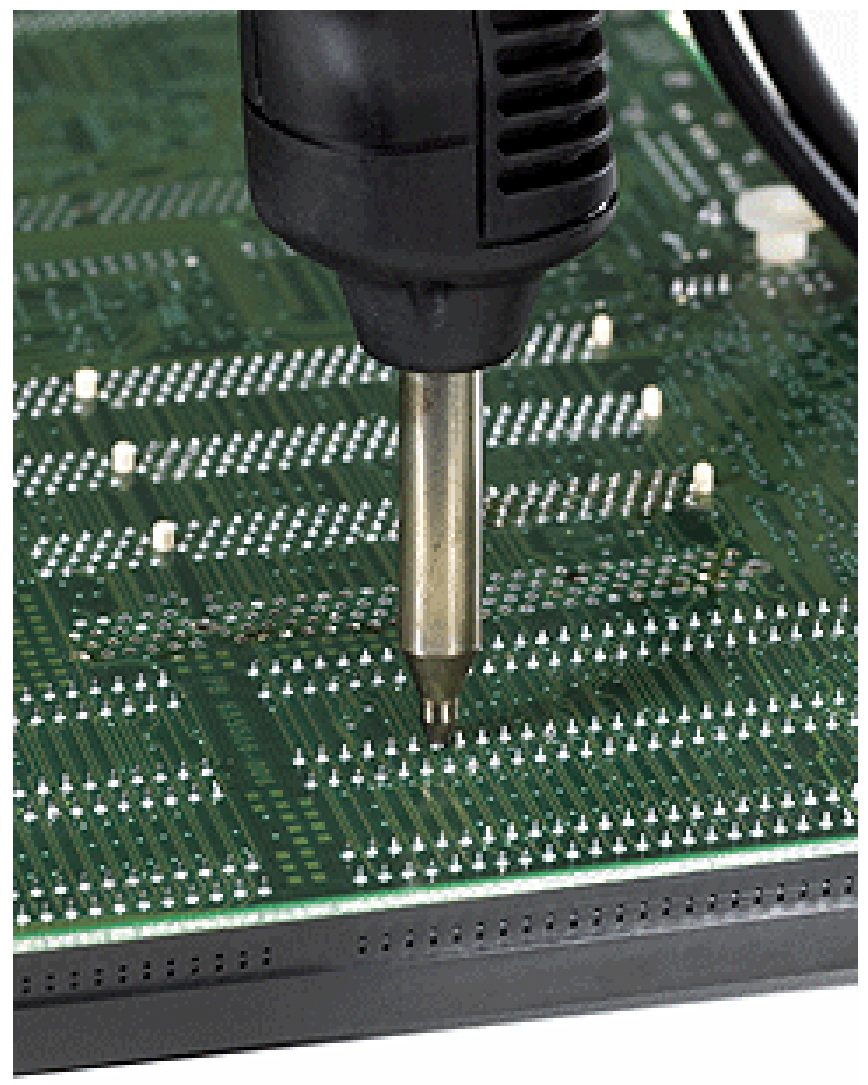

\section{Figure 5 A suction solder removal tool heats a solder joint, drawing molten solder into the barrel of the hand tool [1].}

The removal or conformal coatings and solder joints often leaves a residue on the circuit board lands and around plated through holes. As mentioned, this residue must also be removed to form a solid solder joint for the new component. In normal laboratory or workshop settings, a technician washes the area to be cleaned with large amounts (100-250 $\mathrm{ml}$ ) of a solvent, usually isopropyl alcohol. In enclosed, reduced gravity environments, the use of alcohol, in the amounts cited, present a number of problems. First, alcohol can foul or damage air recirculation and reclamation equipment, which poses serious risks for enclosed environments. The containment of a large amount of liquid in reduced gravity can also present challenges. One way to mitigate both problems is to provide sealed wipes saturated with alcohol or other solvent, such as the small wipes used medically to clean an injection site on a patient. The use of such a wipe limits the amount of solvent used, and thus the exposure of the air circulation equipment to the solvent, and prevents the uncontrolled release of liquid in a reduced gravity environment. Another potential solution is a pen saturated with a cleaning solvent, which eliminates any chance of liquid solvent escaping the work area, and also limits the total amount of solvent that can potentially be used. The user wipes the pen over the circuit board area requiring cleaning. The pens are similar to a highlighting pen.

Board Cleaning After Component Replacement-Postsoldering cleanup of the board is also an important step. This additional cleaning is important due to the use of flux in the soldering process. Flux can be present in the core of a soldering wire, or the user may add a liquid flux to the solder joint area prior to applying heat. The flux performs a final cleaning step of the component lead and circuit board land and helps ensure the flow of liquid solder over the joint components, but leaves a residue after the removal of heat and the solidification of the solder.

This flux residue left over from the soldering process presents two problems. The first problem is that some fluxes are chemically active and slightly acidic. If left on the solder joint the residue can, over time, damage the solder joint, circuit board, and circuit component leads and degrade the performance of the circuit either mechanically or electrically and cause a new failure. Second, the flux residue can interfere with the reapplication of the conformal coating, leading to the conformal coating failing to adhere to the circuit board or reducing the effectiveness of the conformal coating. For these reasons, cleaning the joint areas after soldering a new component is critical to effective repair of a circuit board.

Cleaning the circuit board after soldering is similar to the steps already discussed. In terrestrial settings, operators clean the area around new solder joints with isopropyl alcohol or a similar solvent. The use of these solvents in the enclosed environment of a space habitat poses challenges already discussed. The mitigation schemes - limited volume wipes or pens - are as appropriate in this step of the repair process as in the cleaning step prior to soldering. A possible replacement for cleaning flux residue from a newly soldered joint is to use a no-clean flux. Many manufacturers market this flux for normal industrial uses, and claim the flux residue will not damage circuit or joint components, or interfere with the application of conformal coatings. In practice, these claims will require extensive testing prior to use in long term space missions, ensuring the use of noclean fluxes are appropriate for the specific requirements of space flight and space flight components. 


\section{Soldering TeChNOlogies}

\section{Resistive Soldering Irons}

Resistive soldering irons are basic tools in any electronics workshop, from electronic manufacturing and repair centers to laboratories to home workshops. Basic soldering irons contain a simple heater cartridge and do not contain temperature control or feedback but simply reach a steady state temperature based on voltage and current input and surrounding conditions (i.e. room air). A modified version of such a soldering iron flies on the International Space Station (ISS) and has already been used for simple repairs on orbit $[10,25]$. More advanced soldering irons include tip temperature measurement and control of the heater based on the tip temperature, allowing for user control of the iron temperature as well as compensation for heat loss when in contact with cool, solid solder. An example of this type of soldering iron is an OK Industries model MFR [26].

While specific soldering iron systems vary in dimensions, mass, and capabilities, they typically have the physical characteristics summarized in Table 1.

Table 1 Summary of representative resistive soldering iron system characteristics.

\begin{tabular}{|l|l|l|l|l|}
\hline Manufacturer & Model & $\begin{array}{l}\text { Dimensions } \\
(\mathrm{mm})\end{array}$ & $\begin{array}{l}\text { Power } \\
\text { Input } \\
(\mathrm{W})\end{array}$ & $\begin{array}{l}\text { Temp } \\
\text { Range } \\
\left({ }^{\circ} \mathrm{C}\right)\end{array}$ \\
\hline MKS & MX-500 & $100 \mathrm{X} 200 \mathrm{X} 100$ & 65 & $\begin{array}{l}200- \\
450\end{array}$ \\
\hline MKS & PS-800 & $70 \mathrm{X} 150 \mathrm{X} 100$ & 50 & $\begin{array}{l}200- \\
450\end{array}$ \\
\hline Hakko & FM-202 & $115 \mathrm{X} 175 \mathrm{X} 115$ & 140 & $\begin{array}{l}200- \\
450\end{array}$ \\
\hline Hakko & FX-952 & $115 \mathrm{X} 200 \mathrm{X} 100$ & 75 & $\begin{array}{l}200- \\
450\end{array}$ \\
\hline Weller & WESD51 & $150 \mathrm{X} 115 \mathrm{X} 90$ & 95 & $\begin{array}{l}175- \\
450\end{array}$ \\
\hline
\end{tabular}

Proper tip selection is essential to the effective use of a soldering iron. Tips of different size and shape, with examples shown in Figure 4, accommodate electronic components of various sizes. The use of a variety of soldering iron tips, however, requires increasing levels of skill and experience in the user. The variety of electronic component types leads to a large number of soldering iron tips, which must be stored and accounted for in the limited volume environment of a spacecraft or habitat.
The use of a soldering iron does pose some safety issues for use in space cabins and habitats. The soldering iron tip reaches temperatures of $450{ }^{\circ} \mathrm{C}$, sufficient to melt solder as well as burn unprotected skin or melt or damage plastic. This is a concern that can be mitigated through training and practice, as well as containment during operations.

As previously noted, the ISS carries a soldering iron and work area for performing limited electronic repairs. Figure 6 shows a mock up of the Maintenance Work Area (MWA) with the ISS soldering iron as well as fixtures for securing the circuit board under work. NASA modified the soldering iron for use on the ISS, replacing the original manufacturer's cable with a cable to connect with a battery pack. The image also illustrates the MWA, which encloses the work and tools used during repair, minimizing the chances of accidental damage or injury through contact with the hot soldering iron as well as containing any fumes generated while soldering.

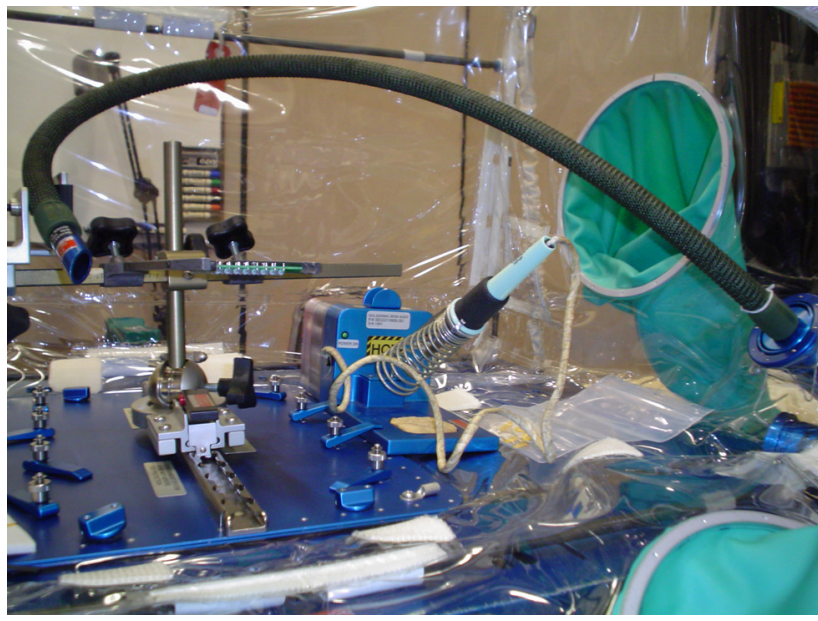

Figure 6: Modified soldering iron within the MWA. The soldering iron cable plugs directly into a battery rather than a power supply. [25]

In addition to the touch safety issue, the use of a soldering iron for electronic repair in space presents other difficulties and challenges, such as operator skill requirements. Soldering irons also are limited to use on components where the leads are exposed and accessible to contact. The use of electronic components such as ball grid array (BGA) chips and similar devices preclude the use of soldering irons in their placement or removal.

Soldering iron systems do have a number of advantages that make their use attractive in space flight applications. The size and mass of the soldering iron system is not particularly large and can be accommodated into a tool kit for electronic repairs. While users will require training and practice in the use of a soldering iron, the training is not extensive and can be focused on components known to be present. The soldering iron currently aboard the ISS attests to the flexibility and usefulness of the tool for repairs. 


\section{Convective Soldering Systems}

Several hand-held devices are available as alternatives to soldering irons. One such device is a convective soldering tool, which dispenses a stream of heated air through a hand piece similar to a soldering iron. This is similar to hand held resistive soldering irons, though the base unit for convective tools are larger and have more mass than resistive tools to account for the air heating and pumping system. Convective tools may also require a backplane heater, which heats an entire circuit board near the solder reflow temperature, with the air stream heating selected joints for component removal or placement. Due to the air heating and pumping requirements, and an additional backplane heater, convective tools require more power than resistive systems. Convective tools, particularly when used with back plane heaters, can heat the leads on a BGA device. Table 2 provides a summary of typical convection soldering irons as well as the size and capabilities of these tools.

The safety issues for a convective soldering system are similar to those for resistive soldering irons. The hot working end of the hand piece, as well as the air stream issuing from the hand piece, pose a burn hazard to the user as well as to the surroundings due to inadvertent contact with the tool. The convective type tool presents an additional hazard from the stream of hot air; this air stream can cause damage at small distances removed from the tool, unlike resistive soldering irons which require touch to cause damage. As with the resistive soldering iron, however, this safety issue can be mitigated in a number of ways. Training and some experience with the tool will decrease the risk of injury or damage, and the use of a containment area such as the MWA described earlier will also help alleviate the risks posed with the use of this tool.

Table 2 Summary of typical convection soldering tools.

\begin{tabular}{|l|c|c|c|}
\hline Manufacturer & $\begin{array}{c}\text { OK } \\
\text { International }\end{array}$ & Hakko & Hakko \\
\hline Model & HCT-900 & FR-801 & 851 \\
\hline Width (mm) & 170 & 160 & 167 \\
\hline Height (mm) & 220 & 145 & 182 \\
\hline Depth (mm) & 140 & 230 & 101 \\
\hline Mass & 4.7 & 4 & 1.8 \\
\hline $\begin{array}{l}\text { Temperature } \\
\text { ( } \text { C) }\end{array}$ & $10-500$ & $100-$ & $100-$ \\
\hline Flow (l/min) & $6-25$ & $5-20$ & 640 \\
\hline Power (W) & 320 & 360 & 85 \\
\hline
\end{tabular}

One disadvantage of the convective soldering tool is the size of the base unit, which tends to be somewhat larger, heavier, and requires greater power than a resistive soldering iron. Backplane heaters, when needed, also require more volume and power than a simple resistive soldering tool. Still, the relative size of the convective soldering system is probably acceptable for a spacecraft application. Convective tools can also require a variety of nozzle tip shapes. Typically, there are not as many nozzle tips for convective tools as tips for resistive tools, and effective management and storage of these tips is not seen as a difficult problem for spacecraft crew. Collateral heating to adjacent components is a potential problem for these systems, if incorrect technique or excessive dwell time is used. This heating can weaken or remove solder joints unintentionally, or damage component leads or circuit board lands. Training and practice will mitigate this problem.

\section{Combined Resistive and Convective Soldering Stations}

A number of companies which offer both resistive and convective soldering tools also offer systems which combine the tools into one package, typically called rework stations. Some stations also include a suction pump for solder removal hand pieces. With these three tools, users are able to remove and replace almost any circuit component, including through hole and surface mount devices, using one base unit and one or more hand tools as the task requires. Table 3 shows the size, power draw, and capabilities of various soldering rework systems.

Table 3 Representative rework stations. These tools include resistive and convective soldering tools as well as suction desoldering tools.

\begin{tabular}{|l|c|c|}
\hline Manufacturer & Weller & Hakko \\
\hline Model & WRS3000VX & $702 \mathrm{~B}$ \\
\hline Width (mm) & 280 & 360 \\
\hline Depth (mm) & 711 & 266 \\
\hline Height (mm) & 290 & 150 \\
\hline Mass (kg) & 11 & 10 \\
\hline Power (W) & 300 & 500 \\
\hline Resistive Tool & Yes, $65-450^{\circ} \mathrm{C}$ & Yes, 200-480 ${ }^{\circ} \mathrm{C}$ \\
\hline Convective Tool & Yes, $1-101 / \mathrm{min}$ & Yes, 23 $1 / \mathrm{min} \max$ \\
\hline Suction Tool? & Yes & Yes \\
\hline
\end{tabular}

Table 3 also shows that the base units for combined rework stations are larger and have more mass than comparable 
single use (resistive or convective) tools. Combining multiple tools into one station, however, offsets this increase in volume and mass, and greatly increases the flexibility for crew in repairing a variety of circuit board components in long-term space missions and habitats. As with the single use systems, the size of rework stations is compatible with the concept of an overall repair kit, to handle multiple contingencies, for crew use.

\section{Infra-Red Reflow Devices}

Another type of hand held non-contact soldering device uses infrared heating as shown in Figure 7. Such systems include a backplane heater and clamp, a hand held wand with an infrared source, and control electronics. Infra-red (IR) reflow devices use two stages to heat solder joints for component removal and replacement. A backplane heater warms the board to a temperature near but below the solder reflow temperature, and re-flow at a specific component is achieved using a wand that supplies additional, focused thermal energy. The wand may be hand held, or in some cases mounted on a translation stage for automated or manual movement. The information presented in Table 4 includes typical examples of IR reflow devices.

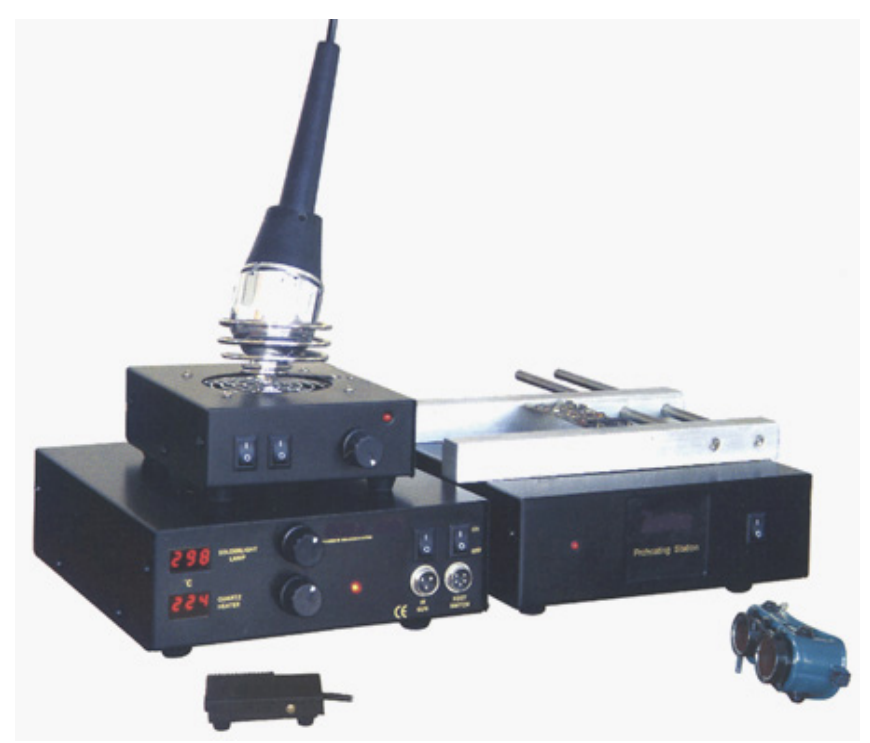

Figure 7 A typical IR reflow device, the PDR X110. The hand held wand stands on its power supply, which in turn rests on the system control and power supply unit. A card holder and backplane heater is to the right of the main power supply [1].

IR reflow devices present some safety hazards. As with other soldering devices, IR reflow systems present a temperature touch hazard. The backplane heater in these devices raises the board temperature (typically around 100 ${ }^{\circ} \mathrm{C}$ ). This hazard may be mitigated through crew training, labeling, and temperature indicators such as temperature sensitive paint or labels, or measurement of the backplane heater and board temperature. Some models and manufacturers include these temperature measurements in the system. Another potential safety hazard is the emitted radiation from the hand held wand, in particular the potential damage to eyesight. This danger will depend greatly on the wavelength spectrum and power of the IR source in the wand; some devices may not emit enough power in wavelengths where the eye is sensitive to damage. In the case where eye damage is a possibility, eye protection in the form of glasses and screens, as well as methods to limit the movement and position of the IR source can mitigate this risk.

IR reflow systems tend to be somewhat larger, and can draw more power compared to resistive and convective soldering tools. Some of the advantages of IR reflow systems, though, include the relative ease of use for a crew member, reducing the amount of training and practice required for effective repairs. Another advantage of this system is a reduction in the risk of damaging components or solder joints near the work area. Applying a mask, such as a strip of aluminum foil, will reflect away much of the energy from the hand held wand, preventing additional heating in undesired locations. The overall heating of the board also helps mitigate the risk of 'thermal shock' to the board, which can occur if localized heating is excessive. IR reflow systems may also be used to remove and replace BGA or other components that are unrepairable with a soldering iron. This capability is one of the design requirements for IR reflow systems in normal industrial use. The placement of BGA components requires the use of visual inspection systems to ensure proper alignment of the component, a provision that must be considered for the repair of BGA systems. The easy management of BGA devices makes IR reflow systems a class of devices to consider for use in long term spaceflight missions.

Table 4 Characteristics of typical IR reflow systems.

\begin{tabular}{|l|l|l|l|l|l|}
\hline Make & Model & $\begin{array}{l}\text { Top } \\
\text { Heat } \\
\text { (W) }\end{array}$ & $\begin{array}{l}\text { Backplane } \\
\text { Heat (W) }\end{array}$ & $\begin{array}{l}\text { Dimensions } \\
(\mathbf{m m})\end{array}$ & $\begin{array}{l}\text { Mass } \\
(\mathbf{k g})\end{array}$ \\
\hline PDR & X110 & 150 & 300 & 600 X 600 & 10 \\
\hline CSI & IR1 & 200 & 500 & 220 X 250 & 10 \\
\hline
\end{tabular}

\section{Laser Soldering Systems}

Laser soldering is a process where a beam of laser light, focused on a single joint or a line of joints, heats and reflows solder, allowing for the placement or removal of electronic components. Figure 8 shows a typical laser soldering system. Laser soldering techniques have received, and continue to receive, much attention from academic and industry researchers; Chang [27] and Messler and Millard [28] are two examples. 


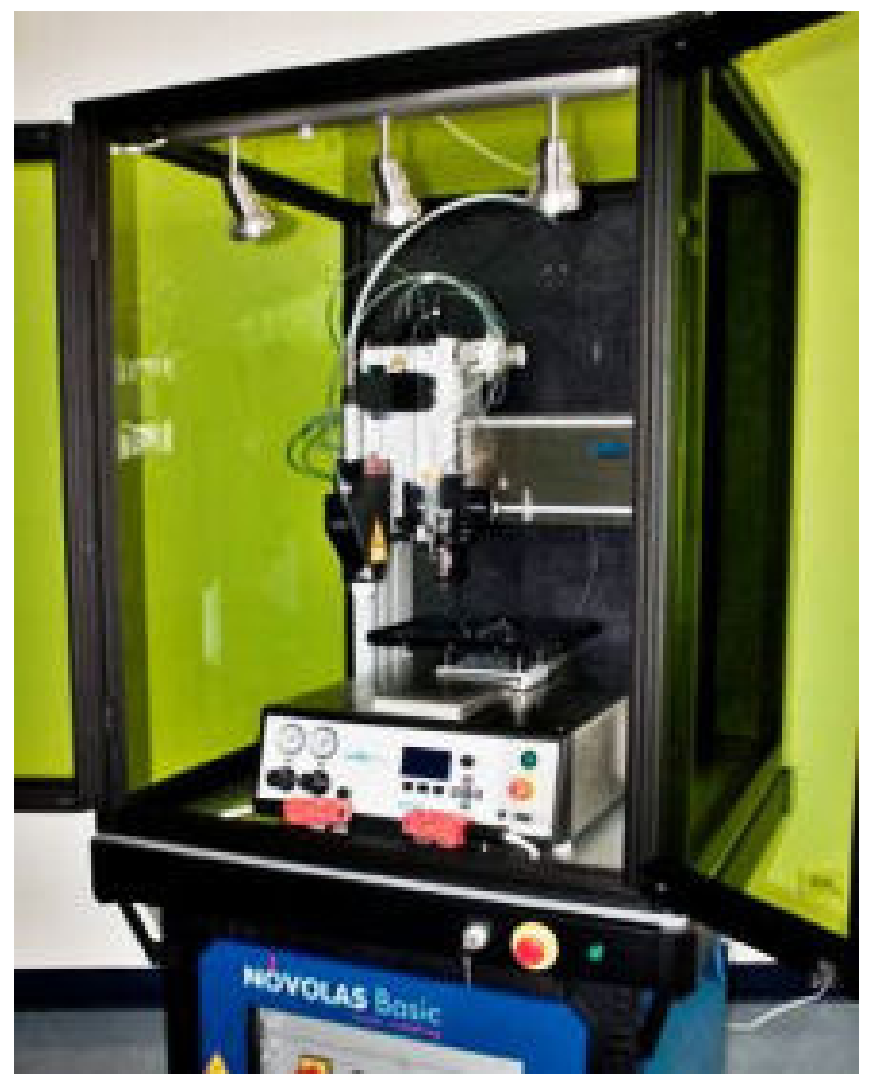

Figure 8 A typical laser soldering system, assembled by EFD. Users place the circuit board in the clamp below the translation stage, and close the enclosure door. Soldering is performed automatically after entering circuit board parameters [1].

The use of laser soldering systems poses some safety hazards for users and others near the system while in use. The first danger is exposure to the laser light. Some systems use light in the visible spectrum, and at high power levels. This includes the use of Class IV lasers, which can cause burns or eye damage with reflected light, not just light in the intended beam path. Mitigating this danger includes the use of eye protection, skin protection, and limiting access to the laser while in use, light covers to block the beam and reflections, or combinations of these techniques.

In general laser soldering systems are not manually operated, requiring additional infrastructure to operate. With the requirement of additional positioning devices and containment, it is not surprising that laser soldering systems are quite large and heavy, compared with other soldering systems.

An example of a relatively small, bench-top system is the Japan Unix Unix-413LII [29]. This robotic unit is $560 \mathrm{~mm}$ x $529 \mathrm{~mm}$ x $1040 \mathrm{~mm}$, with a mass of $39 \mathrm{~kg}$. Additional required equipment includes a laser oscillator unit and laser output control unit, each with dimensions of approximately $300 \mathrm{~mm} \times 400 \mathrm{~mm} \times 200 \mathrm{~mm}$, and a mass of $10 \mathrm{~kg}$. This system uses a $30 \mathrm{~W}$, Class IV laser for solder reflow, and has a maximum current draw of $50 \mathrm{~A}$ at $110 \mathrm{VAC}$.
Laser soldering systems do offer advantages for use in longterm space operations. These systems do not require extensive training and practice to operate. This training is less than that for other soldering processes, particularly hand soldering with a soldering iron or hot air tool. In addition to the relatively low amount of user training required, laser soldering systems reduce the risk of damaging neighboring solder joints or components when heating. The small spot size of the laser light heats a very small area, typically only the solder joint under work. This localized heating does not endanger other solder joints nearby, decreasing the risk of causing additional damage to the circuit board components while under work. Still, the large mass and volume of laser systems make them unlikely candidates for use in a spacecraft environment.

\section{SUMMARY \& RECOMMENDATIONS}

Currently, the International Space Station (ISS) and the space shuttle use orbital replacement units (ORUs) to house electronics systems. In case of a fault, a crew member removes the entire ORU and replaces it with a spare or relies on a backup system. Sufficient replacement ORUs for these missions likely require too much volume and mass to be practical for long duration space missions, such as manned lunar or Martian missions. Providing replacement electronics components, such as integrated circuits, passive components (resistors, capacitors, etc.), and the tools for diagnosis and repair to the crew may allow for recovery from electronics failures during these long duration missions.

A study was performed to examine the current practices, diagnosis instruments, and tools used for electronics repair, and examine their applicability for repairs in long duration space missions. One major component of this study was an examination of three electronics repair case studies, involving NASA, the U.S. Navy, and a commercial manufacturing facility. One of the primary lessons learned from these case studies was the need to influence the design process at an early stage, to incorporate features into the electronic boards and assemblies, which will enable component-level repairs in a service environment. Also, the need for a portable diagnostic system to aid the operator in determining the source of the fault was observed, as demonstrated by the Navy.

The next stage of the study (after the case studies) focused on studying the range of commercially-available repair technologies that address each of the elements in the repair process. This began with an examination of diagnostic devices for finding faulty circuit boards within an ORU and the faulty component on a board requiring replacement. These devices include standard instruments to measure characteristics of the component or circuit, including voltage and resistance measurement, oscilloscopes, and a variety of signal generators and network analyzers. Special attention was given to non-functional testers, such as those 
manufactured by Huntron and DiagnoSYS, as some form of test equipment such as these will probably be required to help the astronaut diagnose a complex board. The final discussion on diagnostic devices focuses on functional testers, which allow users to mimic the inputs and outputs of a circuit board to test for functionality and to find faults. While these functional testers are too large for use aboard a spacecraft, they may find use on the ground for equipment verification and to aid crew members from the ground during a repair.

The trade study also examined the tools required for performing a repair after diagnostics. This began with a discussion of conformal coatings, chemicals which cover a circuit board to protect it from environmental conditions and decrease fire hazards. The methods and tools used to remove the coatings, as well as the general characteristics of different types of coatings were examined.

The methods, tools and techniques for removing faulty components and cleaning the circuit board during preparation for replacement parts was also detailed, with subsequent discussion focusing on various soldering tools, including resistive soldering irons, convective tools, infrared, and laser soldering systems. The advantages and disadvantages (with respect to mass, dimensions, and capabilities) of the tools in a space environment were examined.

The results of this study point to a number of conclusions, regarding implementation of component-level repair of electronics, and certain design considerations that can enable such repairs. These high-level recommendations can be summarized as follows:

1. Design electronics systems for repair, using the best practices of industry coupled with NASA's unique experience with operating in reduced gravity, enclosed environments. NASA should also ensure knowledge about the operation and design of an electronics system remains available, through contracting mechanisms with outside suppliers to providing NASA engineers with functionally equivalent devices for use on the ground.

2. Pursue component uniformity to the degree possible, simplifying the provisioning of future space missions and increasing crew familiarity with the components and repair techniques required.

3. Begin the process of designing electronics and developing tools and procedures for electronics repairs during missions at the earliest stages of spacecraft design. This will allow time to develop expertise about the process, and create a historical basis for future, long term missions.
4. Decide on a uniform conformal coating material for all circuits, most likely a silicone coating. Coating uniformity simplifies the repair process by making removal and reapplication techniques universal across all circuit boards, and silicone coatings are already in use by NASA to protect circuits against environmental and foreign object damage and to help prevent fires or fire spread.

5. Develop a "tool kit" including diagnostic instruments and hand tools for diagnosing and repair electronics circuits at the component level. The diagnostic tools include a PXI bus based system of measurement devices, such as multimeters and oscilloscopes, coupled with a nonfunctional component tester such as those manufactured by Huntron or DiagnoSYS. The crew "tool kit" should include a soldering station including a resistive soldering iron, hot air soldering tool, and solder removal tool with suction, as well as appropriate hand tools.

6. As a part of utilizing non-functional testers, NASA must develop a database of the electronic signature of all components approved for use on flight systems.

The efforts detailed in this report constitute the beginning steps in the process of implementing a repair and maintenance strategy that can help enable greater safety and reliability for manned deep-space missions. The infusion of this strategy into NASA's flight program will require further time and research to determine the proper mix of tools, techniques, and design criteria to enable crew repair capabilities. The best time to begin this process is during the earliest stages of design for the next generation of space vehicles.

\section{ACKNOWLEDGEMENTS}

The authors wish to thank Gary Gorecki (a Lead Electronic Engineering Technician) at the NASA Glenn Research Center for answering questions and performing demonstrations of soldering techniques. The authors also wish to thank the personnel at the Naval Surface Warfare Center Crane, Crane, IN, for their help in researching and writing this trade study, including a site tour, many helpful discussions, and comments on this study during preparation. The authors also wish to thank Huntron and DiagnoSYS for demonstrating their diagnostic devices and answering questions about the performance and capabilities of their products. The author's thanks also goes to Matric for participating in the case study of current repair practices. Project management of this study, part of the Component Level Electronic Assembly Repair (CLEAR) project, is provided by Duc Truong at the NASA Glenn Research Center, Cleveland, OH. CLEAR is a part of the Supportability Project under NASA's Exploration 
Technology Development Program. The Supportability Project manager is Barmac K. Taleghani, NASA Langley Research Center, Hampton, VA

\section{DisClaimer}

Trade names or manufacturer's names are used in this paper for identification only. The usage does not constitute an official endorsement, either expressed or implied, by the National Aeronautics and Space Administration.

\section{REFERENCES}

1 Curreri, Peter A. "Space Resource Utilization and Extending Human Presence Across the Solar System", First Space Exploration Conference: Continuing the Voyage of Discovery, 30 Jan.-1 Feb. 2005, Orlando, FL.

2 Accola, Anne; Fincannon, H.J.; Williams, Gregory J. and Meier, R. Timothy. "Sensitivity study of Space Station Freedom operations cost and selected user resources," IAA, Symposium on Space Systems Cost Estimation

Methodologies and Applications, San Diego, May 1990.

3 NASA's Exploration Systems Architecture Study, NASATM-2005-214062, 2005.

4 Constellation Architecture Requirements Document, NASA-CxP-70000, effective date September 18, 2006.

5 Pettegrew, R.D., Struk, P.M., Watson, J.K., and Haylett, D.R., Experimental Methods in Reduced Gravity Research, NASA-TM 2002-211993 (2002).

6 Pettegrew, R.D., Struk, P.M., Watson, J.K., Haylett, D.R., and Downs, R.S. "Gravitational Effects on Solder Joints", Welding Journal, pp. 44-48 (2003).

7 Struk, P.M., Pettegrew, R.D., Downs, R.S., and Watson, J.K., The Effects of an Unsteady Reduced Gravity

Environment on the Soldering Process, AIAA-2004-1311 and NASA / TM -2004-212946 (2004).

8 Struk, P.M., Pettegrew R.D., Downs, R.S., and Watson, J.K., The Influence Of Gravity on Joint Shape for ThroughHole Soldering, AIAA-2005-0541 and NASA / TM 2005213589 (2005).

9 Watson, J.K., Struk, P.M., Pettegrew, R.D., and Downs, R.S., Experimental Investigation of Solder Joint Defect Formation and Mitigation in Reduced-Gravity Environments, AIAA Journal of Spacecraft and Rockets, accepted and to appear 2006
10 Grugel, R.N.; Cotton, L.J.; Segre, P.N.; Ogle, J.A.; Funkhouser, G.; Parris, F.; Murphy, L.; Gillies, D.; Hua, F.; and Anilkumar, A.V. "The In-Space Soldering

Investigation (ISSI): Melting and Solidification Experiment Aboard the International Space Station", $44^{\text {th }}$ AIAA Aerospace Sciences meeting and Exhibit, 2006, AIAA 2006-521.

11 Anderson, Eric; Easton, John; Oeftering, Richard, Pettegrew, Richard; Struk, Peter. "Current Technologies and Instruments for Electronic Fault Diagnosis and Repair", NASA Technical Memorandum, in press.

12 Combustion Integrated Rack Comprehensive Design Review, FCF-DOC-1421, 2004.

13 Hamilton Sunstrand EPCU Comprehensive Design Review

14 Lawyer, Scott, Analex Corporation, personal communication, 2006.

15 Fox, Dave, Hamilton Sundstrand, personal communication, 2006.

16 Latta, Gary, Naval Surface Warfare Center Crane, personal communication, 2006.

17 Product information, www.teradyne.com

18 Byerly, Kirk, Matric, personal communication, 2006.

19 Horrocks, Hal. "Conformal Coating Removal - What Is The Best Method?", CCRCo white paper, http://www.ccrco.com/study.pdf

20 CCRCO website, http://www.ccrco.com/conformal_removal_workstations.ht $\mathrm{m}$

21 "Workmanship Standard for Staking and Conformal Coating of Printed Wiring Boards and Electronic Assemblies," NASA-STD-8739.1, 1999.

22 "Flammability, Odor, Offgassing, and Compatibility Requirements and Test Procedures for Materials in Environments that Support Combustion," NASA-STD6001, 1998.

23 Product data, http://www.okinternational.com/product_soldering_mfr/mfr _desolder

24 Product data, http://www.cooperhandtools.com/onlinecatalog/literature/55 0294.pdf 
25 NASA information found online at

http://mod.jsc.nasa.gov/df/df53/Databases/Consolidated_To ol_Page/Repair_Kit/US\%20Soldering\%20Kit/Soldering_Kit /US_Soldering_Iron.htm

26 Product information,

http://www.okinternational.com/product_soldering_mfr.

27 Chang, D. U. "Experimental Investigation of Laser

Beam Soldering," Welding Journal, vol. 65, pp 33-41, 1986.

28 Messler, Rober W., and Millard, Don L. "Laser

soldering: New Light on an Old Joining Process," Welding

Journal, vol. 73, pp 43-48, 1994.

29 Product information,

http://www.japanunix.co.jp/ju en/products/unix41312.html.

\section{BIOGRAPHY}

Richard Pettegrew, Ph.D., and John Easton are Staff Scientists at the National Center for Space Exploration Research, at the NASA Glenn Research Center. Peter Struk, Ph.D., is an Aeronautical Engineer at the NASA Glenn Research Center. Eric Anderson is an Electrical Engineer for ZIN Technologies. Pettegrew and Struk have been working on soldering and related electronics repair issues in reduced gravity environments since 2000, with considerable experience aboard NASA's Reduced Gravity Aircraft. That early work has led to the formation of the CLEAR project, which Easton and Anderson have since joined. 